\title{
Promoting Student's Problem-Solving Skills through STEM Project-Based Learning in Earth Layer and Disasters Topic
}

\author{
Firdha Sarah Kartini ${ }^{1 *}$, Ari Widodo ${ }^{2}$, Nanang Winarno ${ }^{1}$, Lia Astuti ${ }^{3}$ \\ 1Department of Science Education, Universitas Pendidikan Indonesia, Bandung, Indonesia \\ 2Department of Biology Education, Universitas Pendidikan Indonesia, Bandung, Indonesia \\ ${ }^{3}$ Department of Computer Science and Information Engineering, National Quemoy University, Kinmen, Taiwan \\ *Corresponding author: firdhasarahk@gmail.com
}

\begin{abstract}
Located in the Pacific Ring of Fire, Indonesia is endangered by natural disasters. Through the changing of learning activity in a proper way by the application of STEM Project-Based Learning, future generations are expected to develop the knowledge and thinking skill to solve the problem. Therefore, this study aimed to investigate implementing STEM Project-Based Learning on student's Problem-Solving Skills. This research used a Pre-Experiment method with a One-Group Pretest-Posttest design and essay questions as data collection tools. In this research, 307 th-grade students at one school in Bandung, Indonesia, were chosen as the participants. The data analysis showed significant improvement between student's Problem-Solving skills pretest and post-test ( $\mathrm{N}$-Gain=0.73). In addition, Idea-Finding is the most significant improvement during the Fact-Finding on the lowest. Based on the result, STEM Project-Based Learning is recommended to improve students' Problem-Solving Skills since they can use their integrated knowledge to solve a real-world problem.
\end{abstract}

Keywords STEM Project-Based Learning, Problem-Solving Skills, Earth Layer and Disaster

\section{INTRODUCTION}

Indonesia has to struggle with the risk of volcanic eruption, earthquake, flooding, and tsunami since Indonesia is situated on the Pacific Ring of Fire within the Australian Plate, Eurasian Plate, Pacific Plate region, and the Philippine plate that makes the nation becoming the world's most seismically active region. In Indonesia, over 677 earthquakes have occurred in the past 365 days. Based on Earthquake Track (2020), the 1,628 accidents, 60 people died, 545,000 were displaced, more than 9,000 were destroyed, and hundreds of public buildings have been destroyed in the last six months (BNPB, 2020). This phenomenon shows that problem-solving in disasters is still low with a large number of victims repeatedly.

Through education, disaster risk reduction by developing student attitudes, skills, and knowledge can be gained. In facing unexpected challenges, we must prepare the future generation to solve real-world problems such as natural disasters by studying the phenomenon, using their expertise, and adjusting under conditions to the latest modifications. However, that will never happen because we have never improved how the learning practice is carried out. In 2019, Indonesia had a PISA ranking of 396 points in education, compared to an average of 489 in OECD countries (OECD, 2019). It indicates the low quality of Indonesian education. One of the reasons is because the learning system only focuses on remembering. Students now have excellent memorization, but they would not be able to adapt what they have learned to real-world problems (Arisanti, Sopandi, \& Widodo, 2016).

The low quality of Indonesia education also affects the percentage of students' problem-solving skills in Central Java. The percentage was $52.93 \%$ based on the test and indicated that students' problem-solving skill is categorized low (Jua, Sarwanto, \& Sukarmin, 2018). Problem-solving is defined as a cognitive-affectivebehavior method involving finding the right ways to cope with daily life problems, and it leads people to solutions for the problems (Maydeu-Ollivares \& D'Zurilla, 1997). Problem-solving is a crucial skill to affect any move in life, from essential to complex (Deniz, 2004). Use the Problem Solving Skill Test (PSAT) to assess the pupils' problem-

Received: 24 August 2020

Revised: 8 March 2021

Published: 5 July 2021 
solving abilities and the abilities of science-processing. Chang and Weng (2002) designed and constructed the PSAT according to the Imaginative Problem Solving (CPS) model, emphasizing convergent (or critical) and divergent (or innovative) thinking skills of students contained by the following four-stage problem-solving processes; (1) Fact-finding stage: students can find the number and variety of facts, (2) Problem-finding stage: the students can recognize problems and degree of clarity problems, (3) Idea-finding stage: students can put forward with number and variation of ideas and degree of creativity of the ideas; (4) Solution-finding stage: the students can propose rationality, accuracy, and the possibility of solutions.

Indonesia Curriculum emphasizes interdisciplinary dimensions that promote the learning process using logical, conceptual, and systemic approaches. Triggered by documented low-performance mathematics and science rates, a new curriculum strategy is being created and named STEM education. The STEM curriculum strives to teach independent and specific skills of science, engineering, and mathematics. Another method to address the essential for STEM Education with practical action is introducing STEM Project-Based Training, which relates to the learning paradigm constructed on the STEM Education approach and combined with the project-oriented set of course templates (Tseng, Chang, Lou, \& Chen, 2013). STEM Project-based learning allows students to cultivate idea understanding and critical thinking skills in keeping with the theory of lifelong learning that corresponds to the four foundations of universal education; namely learning to know, learning to do, learning to live together, and learning to be (Arisanti et al., 2016). STEM Project-Based learning is divided into five stages, which can be adopted for the teacher based on Lou, Chou, Shih, and Chung (2017) described as the preparation stage, implementation stage, presentation stage, assessment, and correction stage. STEM Projectbased learning also combines science curriculum and engineering design concepts; this combination of design principles develops applicability in the real world.

Many studies have been conducted as concerns implementing STEM Project-Based Learning to see its effectiveness, including investigated Problem Solving Skills such as Hanif, Wijaya, and Winarno (2019), also research on improving student's creativity by using STEM Project-Based Learning. Apriyani, Ramalis, and Suwarna (2019) have also researched analyzing the student's Problem-Solving Skills using STEM-based learning on direct current electricity. The research on the development and validation of science, technology, engineering, and mathematics (STEM) is based on instructional material already carried by Gustiani, Widodo, and Suwarma (2017). The study using STEM ProjectBased Learning on student concept mastery and Creativity skills was also have done by Arisanti et al. (2016). Nonetheless, there have not been several studies on STEM Project-Based Learning research found to investigate student's Problem-Solving Skills. Besides, student's problem-solving skills in disasters, especially earthquakes, are still lacking. Due to the demand for improving students' problem-solving skills, the researcher decided to conduct the research titled "Promoting Student's Problem-Solving Skills through STEM ProjectBased Learning in Earth Layer and Disasters."

\section{METHOD}

\subsection{Research Design}

This study's research method is the pre-experimental method, which uses one research group without the classroom's control. This research method is appropriate for this research, which investigates the STEM ProjectBased Learning as the independent variable for students' problem-solving skills as the dependent variable in learning earth layers and disaster topics.

One group pretest posttest is the research design used, which observed and measured the impact of the treatment not only in the last part but also before the STEM Project-Based Learning treatment is applied. Therefore, the research design to compare the pretest result to know their prior knowledge and after the concept gave the treatment of the final post-test from one group is possible. The design is as shown in Table 1.

\subsection{Participant}

The characteristic of the selected schools is that have implemented the 2013 National Curriculum in the learning process. The location where this research was carried out is in Bandung City, Indonesia. All 7th-grade students were the population of this study, and 30 students from School $\mathrm{X}$ are used as the sample. Convenience sampling is the sampling method used in this research. The selected participants are chosen because they are available to be studied. There are 13 male and 17 female students with an age average of 12-13 years old. The distribution of participants shown in Table 2.

\subsection{Research Instrument}

In this research, the students' problem-solving skills were measured based on criteria on the Problem Solving

Table 1 Experiment design

\begin{tabular}{lll}
\hline $\mathbf{O}$ & $\mathbf{X}$ & $\mathbf{O}$ \\
\hline Pretest & Treatment & Post-test \\
\hline
\end{tabular}

Table 2 Participants distribution

\begin{tabular}{|c|c|c|}
\hline \multirow[b]{2}{*}{ Gender } & \multicolumn{2}{|c|}{ Experiment Class } \\
\hline & $\begin{array}{l}\text { Number of } \\
\text { Students }\end{array}$ & Percentage \\
\hline Male & 13 & $43.3 \%$ \\
\hline Female & 17 & $56.7 \%$ \\
\hline Total & 30 & $100 \%$ \\
\hline
\end{tabular}


Ability test (PSAT) by Chang and Weng (2002). The PSAT was developed and built the Creative Problem Solving (CPS) model (Osborn, 1963) that underlines the convergent (or critical) and divergent (or creative) thinking skills of students in the following four-stage problem-solving processes: fact-finding, problem-finding, idea-finding, and solution-finding (Treffinger, Isaksen, \& Stead-Dorval, 2005). All questions are adapted from the earthquake problem titled 'BMKG: Jepang Sudah Wajibkan Bangunan Anti Gempa Sejak 1990' in CNN Indonesia (2019).

The objective is then arranged and prepared before being validated, judged by the experts, and tested to students who have learned the earth layer and disaster topic before. In this situation, they are the grade 9 students from 3 classes. The validation of the test consists of a validity and reliability test using ANATES V4. Consisting with 5 open-ended essay questions, the items are reliable with the reliability value $(\alpha)=0.78$ and the validity value $(r)=0.63$. After being judged by experts, Problem Solving Skills objective test is deemed suitable and therefore does not change. Students' Problem-Solving Skills pretest and post-test were then given a score to see the difference in essay questions as quantitative data.

\subsection{Data Analysis}

Each correct answer for a question is worth four marks in the objective test. However, an incorrect answer will be 0 marks. As for Problem Solving Skills, that has four components to be measured. Every component has different total marks. The most suitable answer is worth four marks, while a not related answer will obtain 0 marks.

To further investigate how STEM Project-Based Learning has a significant outcome on student's problemsolving skills, a statistical approach has been used to measure the data derived from the pretest and post-test of students. The summary of the analysis results is presented in Table 3. The statistical analyses used in this analysis used the program SPSS version 25.0. The normality test results are shown in Table 4, on the value of the ProblemSolving skills test. Because of the sig value. $(\mathrm{P})$ is more significant than 0.05 ; a significance value gained is 0.345 for the pretest data and 0.114 for the post-test data. It can be assumed that the data are normally distributed.

From the homogeneity test results shown in Table 5, the STEM literacy pretest and post-test data have a significance value more significant than the $\alpha=0.05$, which is 0.043 , so that the data has a homogeneous variance. Therefore, a null hypothesis (H0) is that there is no difference in mean scores between pretest and posttest. Meanwhile, an alternative hypothesis (HA) is a difference in mean scores between pretest and post-test. According to the Paired Samples Test output shown in Table 6 , the significance value (2-tailed) is 0.000 , and it is less than 0.05 , as explained beforehand. Thus, the null

Table 5 Homogeneity test of students' problem-solving skills

\begin{tabular}{llll}
\hline Levene Statistics & df1 & df2 & Sig \\
\hline 0.085 & 1 & 50 & 0.043 \\
\hline
\end{tabular}

Table 3 Summary of student's problem solving skills objective test

\begin{tabular}{llll}
\hline \multirow{2}{*}{ Component } & & Problem Solving Skills & \\
\cline { 3 - 4 } & & Pretest & Post-Test \\
\hline Participant & & 30 & 30 \\
$\bar{x}$ & & 69 & 92 \\
SD & & 8.36 & 7.19 \\
Highest Score & & 87 & 97 \\
Lowest Score & Significance & 0.345 & 67 \\
Normality Test (Shapiro-Wilk) & Interpretation & Normal & Normal \\
& Significance & 0.043 & \\
Homogeneity Test (Levene's Test) & Interpretation & Homogenous & \\
& Significance & 0.00 & \\
Paired T-Test & (2-tailed) & Significant & \\
\multirow{2}{*}{ Normalized Gain Test } & Interpretation & 0.73 & \\
\hline
\end{tabular}

Table 4 Results of normality test on students' problem-solving skills

\begin{tabular}{|c|c|c|c|c|c|c|}
\hline \multirow{2}{*}{ Treatment } & \multicolumn{3}{|c|}{ Kolmogorov-Smirnova } & \multicolumn{3}{|c|}{ Shapiro-Wilk } \\
\hline & Statistic & df & Sig. & Statistic & df & Sig. \\
\hline Pre-test & 0.211 & 30 & 0.116 & 0.930 & 30 & 0.345 \\
\hline Post-test & 0.184 & 30 & 0.200 & 0.895 & 30 & 0.114 \\
\hline
\end{tabular}


Table 6 Result of paired t-test sample

\begin{tabular}{lllll}
\hline \multirow{2}{*}{ Treatment } & Paired Differences & & \\
\cline { 2 - 5 } & $\mathbf{9 5 \%}$ Confidence Interval of the Difference & $\mathbf{t}$ & $\mathbf{d f}$ & Sig \\
\hline Paired Pretest-Posttest & -19.247 & -12.533 & 29 & 0.000 \\
\hline
\end{tabular}

Table 7 Interpretation of indicator of problem-solving skills

\begin{tabular}{llll}
\hline Pretest & Post-test & N-gain & Interpretation \\
\hline 69 & 92 & 0.73 & High \\
\hline
\end{tabular}

hypothesis (H0) is rejected, and the alternative hypothesis $(\mathrm{Ha})$ is accepted. The interpretation is that there is a difference between the mean scores of the pretest and post-test. After that, the $\mathrm{N}$-gain score test is performed by calculating the scores pre-and post-test. $\mathrm{N}$-gain score gained is 0.73 , which in the range of $0.7 \leq \mathrm{N}$-gain scores $\leq 1$, and the category is a significant improvement based on the Hake (1998) criteria shown in Table 7.

\subsection{Research Procedure}

There are three stages in research procedures. The first stage is the preparation stage, which includes problem identification and educational bodies' problem in the teaching and learning process. It also decides the investigated same independent and dependent variables to be in the research. Next, the researcher needs to reflect on some components that will improve the research's strength, such as curriculum, learning instruments, and teaching schedules. After that, the researcher arranges research instruments and learning tools that will be used. Finally, the experts judge those instruments and do the trial test of an objective test instrument to discover the instrument's quality.

The next stage is the implementation stage by conducting the STEM Project-based Learning in three meetings, involving four stages, which are the preparation stage, implementation stage, presentation stage, and evaluation stage. The learning activity was carried online due to the COVID-19 pandemic, which allowed us to conduct the learning activity as usual. The application use is zoom meeting and Google classroom. The teacher and student will also use the WhatsApp application as the communication tool.

Pretest starts the first meeting activity to identify preliminary student skills. On the central part, the steps of STEM Project-based learning are conducted. They are started by the preparation stage, where the student has introduced the concept material and problem-related to the scientific phenomenon around them to investigate. In the second meeting, there is the implementation stage where students need to generate the solution by integrating their knowledge in science, technology, engineering, and mathematics. Finally, they have to make the project design and made the prototype on their home. The presentation stage was also conducted in this second meeting. The selected student need to present their idea while the other gives feedback. The last meeting is used to conduct the evaluation stage. The student and teacher give a score, evaluate the weakness, and give some recommendations for a better future project. The posttest is given at the end of the learning activity to measure the result of the implementation of STEM Project-based Learning, and the data gained is analyzed.

\section{RESULTS AND DISCUSSION}

According to Whitten and Graesser (2003), the central aspect that affects problem-solving skills is promoting students' capability to explain problems and analyze solutions. The learning activity using STEM Project-Based Learning in this research through four stages is the preparation stage, implementation stage, presentation stage, and evaluation stage. This stage requires students to seek and find out the general information and the data related to the earthquake. Then, the teacher provides several questions to increase students' ability to think critically. In this stage, the problem-solving skills process emphasizes fact-finding and problem finding. This activity lets the student identify problem-related to scientific phenomena and the impact on the environment. The next stage of STEM Project-Based Learning is the implementation stage. Students have to use their knowledge in Science, Technology, Engineering, and Mathematics to generate a solution to the problem. While in this stage, idea-finding and solution finding of the problem-solving process in a student is developed. Finally, the student is trained to make the prototype solving problems, which is an earthquake-resistant building. In process making, students will face several problems and use their scientific knowledge to solve them.

From four aspects shown in Table 3, almost all aspects are categorized as a significant improvement in Hake's Rule based on their normalized gain result. This result represents in general, student's problem-solving is improved, and STEM Project-Based Learning is effective to enhance problem-solving skills. It is shown that the idea-finding aspect has the highest normalized gain in 0.94 , represent the improvement of student generating ideas to solve the problem is the most influence on the student problem-solving process. This result is because STEM Project-Based Learning trained students to solve daily life problems through doing the project. In comparison, the fact-finding aspect showed the lowest improvement than others. The normalized gain is 0.62 , although categorized as a medium improvement based on Hake's Rule, this aspect has the smallest result. However, 


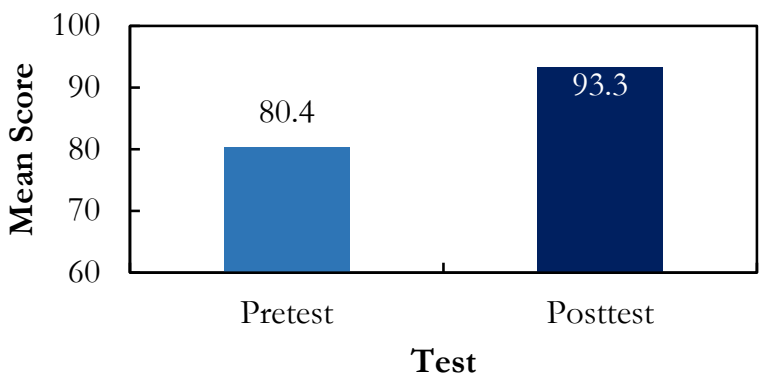

Figure 1 Students' fact-finding result

it can be said that the student problem-solving process has the positive enhancement that they can make a connection on cognitive knowledge on STEM ProjectBased Learning activity (Bhakti et al., 2020). All the problem-solving aspects will be described in further detail.

\subsection{Fact-Finding}

According to Chang and Weng (2002), the fact-finding aspect refers to the problem-solving process requiring students to determine the information available and relevant to the topic. Students more emphasized investigating the fact that exist in daily life as much as they can using observation and investigation. Students also need to understand the consequences to the environment. The result is measured by the open-ended essay question in a case study on Indonesia's earthquake and compared to other countries. Students are asked to explain their perfection due to the problem offered. The result is shown in Figure 1.

There is an improvement in students' fact-finding aspect after implementing STEM Project-Based Learning, according to Figure 1. Student results are classified as high in the pretest, that the mean score is 80.4 , then it increases by 13.3 points to the mean score of 93.3 in the post-test. Based on Table 1, the Fact-finding aspect has the lowest improvement. Nonetheless, this aspect has an N-gain score of 0.63 , categorized as a medium improvement based on Hake's Rule.

The study carried out by Nuraziza and Suwarna (2018) revealed that the percentage of the average score obtained by student's fact-finding is $44.44 \%$, and it is included in the sufficient category. The students' science problemsolving abilities for the project-based learning model group (MPBP) were 26.67\% highly qualified, 23.33\% sufficiently qualified, and $50 \%$ less qualified. The scores of students' science problem-solving abilities for the conventional learning model group were $10 \%$ sufficiently qualified, $40 \%$ low-qualified, and $50 \%$ very poorly qualified. The average achievement of each problemsolving component in the project-based learning model (MPBP) was categorized sufficiently, while the conventional model learning is in the poor category. The STEM Based Learning activity was applied in one junior high school in Bandung. After the implementation, the
Based on the results of your understanding of the text above, state the cause of the large number of earthquake victims in Yogyakarta!

The cause of the large number of casualties in Yogyakarta is the lack of awareness of the surrounding community regarding earthquake preparedness. they did not develop the latest innovations in dealing with earthquakes.

With the same earthquake strength, but the casualties incurred are very different. Mention the cause of the low number of casualties from the earthquake in Suruga!

Japanese citizens have obliged their people to build earthquake-resistant buildings, which are buildings that can withstand and protect objects in them from earthquake shocks. so as to minimize casualties due to the earthquake shock

Figure 2 Student's answer in post-test of fact-finding question

students can find new facts related to the waste in their environment.

Throughout the fact-finding aspect, students are inquired to examine their understanding of the question and identify or mention all the components of information they may think about (Treffinger et al., 2005). In this research, students have faced real-life study, and students can mention the fact and the information they get in the case discussed, as seen in Figure 2. Students can already identify the number and variety of facts to the earthquake in Yogyakarta and Suruga. They can use their prior knowledge to mention that the earthquake victim in Yogyakarta is higher than in Suruga, even though it has the same earthquake strength in Skala Richter.

It is showed from student answers on the post-test in Figure 2. Their ability to analyze the scientific phenomena includes Five Ws and H (Who, Why, What, When, Where, and How). They also need to make an effort to find out what happens behind any problem, as a parallel with the statement that students make a pattern on their efforts in addressing any problem (Heffernan \& Teufel, 2018).

However, student development in this aspect is helped in STEM Project-Based Learning on the preparation stage. Students are introduced to earthquakes and other phenomena related to the earth layer and disaster deeply in this stage. Many information relevant to the earthquake is provided through several engaging learning media such as video, animation, and PowerPoint. However, it is impossible to identify it directly because the learning activity is running online. The information gained on the preparation stage will be used on the next STEM Project-based learning stage to generate their creative thinking skill to propose the solution. This evidence is in line with Cropley (2006) that states fact-finding is the root of creative ideas.

In project making, the fact-finding ability is also trained on the first stage of the earthquake-resistant building-making process. Students are introduced to one 


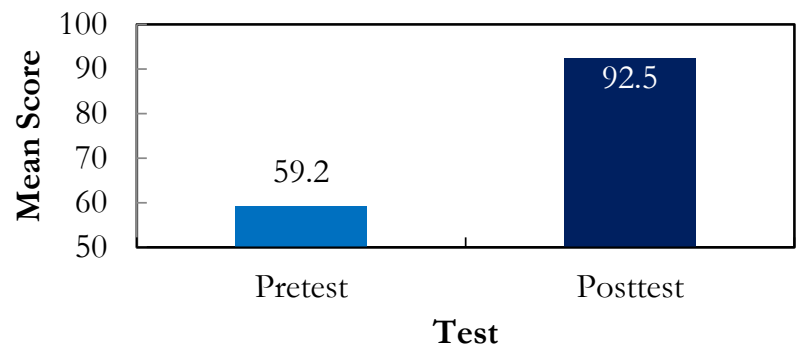

Figure 3 Students' problem-finding result

video about the application of earthquake-resistant buildings in real life. They are forced to find out the various information about their project before making the prototype by themselves. After the teacher showed the video, students are asked some questions about the earthquake-resistant building directly? How is it works? What is needed to build it? Where is it used? And other related questions. In the learning meeting, some students can answer it. While the other needs a little time to think to answer it. This result can be concluded that STEM Project-Based Learning can facilitate student fact-finding ability to improve because it is not only used for the learning topic but also in the project making process, so this results in the post-test increase.

\subsection{Problem-Finding}

The student problem finding focused on recognizing the number of problems and the degree of clarity of describing problems (Chang \& Weng, 2002). The teacher promotes the chance of students understanding, investigating, and discovering answers to their problems. Students must be able to find the central problem through the text or photo presented by the teacher. Furthermore, the targeted source can be on the internet, reviews, books, and tests can be used to improve comprehension. Problem finding value projected idea finding quality, however for another task, the quality of the problems establish expected both idea finding excellence and novelty. Nonetheless, several researchers asked participants to develop some potential issues (Arreola \& Reiter-Palmon, 2016).

There is an improvement in students' problem-finding aspect after implementing STEM Project-Based Learning, according to Figure 3. Student result classified low since it is under the minimum criteria score in the pretest, which is the mean score is 59.3 , then it increases to the mean score of 92.5 in the post-test. The fact-finding aspect improves in the medium category with an $\mathrm{N}$-gain score of 0.81 , categorized as a significant improvement based on Hake's Rule. According to the student, the problem raised is close to their daily life. Then the student has a clear idea about the problem and its impact.

Another study has been carried out on undergraduate students participating in the Information Technology Program registered in the academic year 2016 for the

\begin{abstract}
Earthquakes are unpredictable. However, the losses incurred from this disaste were enormous, from casualties to material losses. Mention other problems that can occur in environmental, health, and socio-cultural aspects if disaster management is not handled immediately! Include your reasons

Environmental aspects: damage to development, loss of biological resources, damage to residents' homes, damage to ecosystems

Health aspects: when an earthquake occurred, not a few casualties or injuries needed media assistance, while the nearest hospital and its facilities were also damaged by the earthquake. so that people find it difficult to get first aid.

Socio-cultural aspects: poverty because people lose material, disruption of the people's economic system
\end{abstract}

Figure 4 Student's answer in post-test problem-finding question

Strategic Data Management exam, carried by Netwong (2018). The relation of the learning achievement in problem-solving of the experiment between pretest and post-test was higher than the pretest at the point of significance of 0.05 Problem-solving skills after study. STEM education can develop the problem-solving skills of the students. The learners broke the community into project-dependent problems in the first phase. The implementation of the project was to establish novel approaches by using information technologies across organizational challenges. The student shared his or her views when carrying out the study. It can promote a learning culture by practice, work, project, and work more as a team.

The high score of the problem-finding aspect indicates students' ability to find the study case's main problem in the learning activity. If students already possess these skills, they can automatically formulate problems resulting from errors in disaster response behavior. To evaluate student problem-finding, they are given the news of the real cause of Indonesia's earthquake. Then, they are required to analyze and mention the problem that may happen because of the earthquake. According to Figure 4, students can mention their analysis in three aspects of life in detail. First, students can be highlighted by a reformulation of problem statements that contain only the main problem and finally found the cause. Thus, following Schlegel et al. (2019) statement, STEM learning increases efficacy in identifying potential causes of problems.

This result can be the cause of STEM Project-based learning to help students identify and analyze earthquake cases deeply. An alternative to the old-style curriculum, where learning is usually highly segregated by subject field, is the interdisciplinary STEM Project-Based Learning. In STEM Project-Based Learning, learning is more intuitive and appropriate for developing a deep understanding of the definition. Therefore, in real life, the principles individually taught can then be remembered as valid 


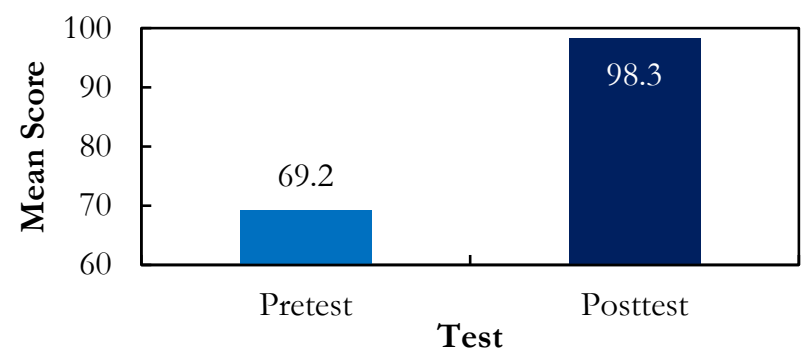

Figure 5 Students' idea-finding result

experiences. This evidence can motivate students to study more (Guthrie, Schafer, Von Secker, \& Alban, 2000).

The student has a high motivation to solve the problem related to the earthquake because the phenomenon is familiar with their daily life. Some of them already experience it and become the victims of this disaster. This finding is parallel with Tseng et al. (2013) revealed that STEM Project-Based Learning could develop students' learning motivation, create meaningful learning, help students solve daily life problems, and support future careers.

The STEM Project-Based Learning trained students to develop their ability in problem-finding on the implementation stage. This stage is where the student can build their project by themselves. There will be many problems to make this project do as it is dreamed of, the most substantial building during an earthquake. They are faced with two big problems: making the building comfortable to live in, the beautiful shape, and the material needed to make it. From several problems in this stage, they concluded that the main problem is choosing the suitable material for their project. This result shows that students already have a great problem-finding ability to use their knowledge to identify and find the central problem by integrating their knowledge in science, technology, engineering, and mathematics. Lou et al. (2014) stated that PBL-STEM would enable students to systematically integrate the facets of engineering and technology and gain in-depth knowledge of science and mathematics to improve students' expertise and experience to apply their knowledge to everyday life.

\subsection{Idea-Finding}

The amount and diversity of ideas planned by the student using the student's creative ideas refer to the ideafinding ability (Chang \& Weng, 2002). This stage calls for idea-producing and idea-development to pursue proposals. The development of ideas involves dreaming up preliminary proposals as soon as possible.

According to the pretest and the post-test results in Figure 5, idea-finding improvement shows a big difference with 29 points. In the pretest, the mean score is 69.2 and shows that the idea-finding of students is low. After the application of STEM Project-Based Learning,
Based on the discourse in the text above, there is a huge difference between the earthquake victims in Yogyakarta and Suruga. This occurs because of differences in disaster preparedness. Give at least three alternative solutions that can be applied by the community, especially those in earthquake-prone areas!

1. renovating the house, making the building foundation earthquake resistant

2. Know the open space outside the home that is safe

3. prepare important items in a first aid bag

4. perform earthquake simulations

5. Have a list of important contacts

Figure 6 Student's answer in idea-finding question

the post-test highly increase due to the result shows 98.3. The $\mathrm{N}$-gain score of 0.94 also shows the highest students' improvement in the Problem Solving Skills aspect based on 14.3 and categorized as a significant improvement in Hake's rule.

Another study carried by Yuliati, Riantoni, and Mufti (2019) in Tulungagung, East Java, found that after the performance of STEM Project-Based Learning, the experiment class has a higher $\mathrm{N}$-gain score and categorized moderate improvement since it is 0.43 bigger than the control class, which only 0.19 and categorized low. Students in the STEM Project-Based Learning class developed a science product to resolve a question indicated in the worksheet for the students. Once a group displayed their concept in front of the community, it only allowed other groups to provide suggestions, opinions, or critique. Only instructions to elaborate on the result of the stated problem are included in the worksheet. The different treatments in the two classrooms triggered different behaviors culminating in the significant enhancement in both courses' problem-solving abilities.

The high score on the post-test shows that students already possess these skills, then students can find ideas that might be used to solve problems that arise from a lack of readiness to face earthquakes. The idea revealed is produced because of the deep understanding of the topic's principle and student creativity. A positive relationship between problem finding and idea finding outcomes of undergraduates was initiated by Arreola and Reiter-Palmon (2016), but this correlation was different across diverse problem tasks. The previous result on the problem finding gives the good representative, which influences the idea-finding aspect to be greater than others. In Figure 6, students can propose some possible ideas for the earthquake problem in detail. These proposed ideas are from their point of view and from adult and government views in facing these problems. This evidence can be concluded that STEM Project-Based Learning can improve student idea-finding ability. 


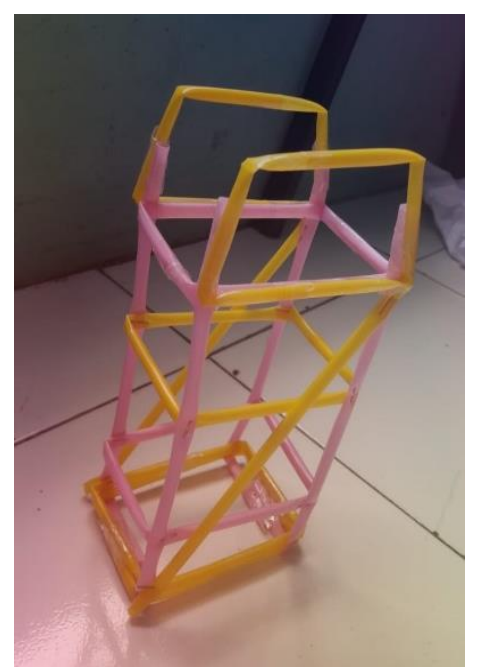

Figure 7 Student earthquake resistant building prototype

In this research, the STEM Project Based-Learning trained students to develop their creativity through the implementation stage to use their knowledge in science, technology, engineering, and mathematics to solve the problem. In addition, it will enable students to have more responsibility for their learning. This result is in line with Capraro and Jones' (2013) statement that for building a deep understanding of the concept, STEM Project-Based learning can also meet the diverse learning needs by enabling learners with responsibility towards their learning.

Students also focused on increasing their idea-finding related to the earthquake-resistant building along the project-making process in STEM Project-based Learning. This stage involves students designing and assemble the prototype by a hands-on activity. The earthquake-resistant building should have a strong foundation and the lightest material on its wall. Regarding this problem, students already propose some possible ideas to be used in their future prototype. All these ideas are directly presented in a learning activity in a zoom meeting, on the presentation stage of STEM Project-Based Learning. Students can describe their idea clearly. Student ideas on earthquakeresistant building prototypes can be seen in Figure 7. This student used straw because it is the lightest material, and shear walls using a yellow straw are used on this design to reinforcing a building. The student answer is relevant to

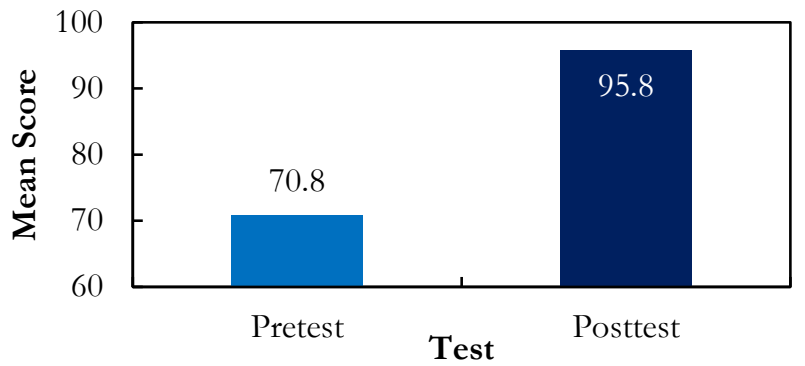

Figure 8 Students' solution-finding result
BigRentz (2020), which states that to resist collapse, buildings require rearranging the forces that travel through them during a seismic event used, sheer walls, cross braces, diaphragms, and moment-resisting edges are central to strengthening a building.

\subsection{Solution-Finding}

Students are asked to consider their innovative ideas and select the most creative ones during the solutionfinding process. Some studies explore the identification of new ideas in the past few years (Benedek et al., 2016). This aspect refers to evaluation and adoption. Approval calls for determining and implementing the final solution.

Grohman, Wodniecka, and Kłusak (2006) led an exploratory analysis of how the self-rating of primary school students' creativity correlated with official creativity scores on a visual, verbal, and science mission. Outcomes revealed students could distinguish their success through realms of innovation and across levels of efficiency. In addition to that, their scores were favorably correlated with the professional imagination scores. Under this Grohman, Wodniecka, and Kłusak's (2006) analysis, the proposals' creativity was reviewed. However, the innovation elements can be isolated to examine why some innovation aspects are valued rather than others. Students are then able to apply the approach they have discovered by selecting the most innovative ideas.

There is a significant improvement in students' solution-finding aspect after implementing STEM Project-Based Learning, according to Figure 8. The normalized gain is 0.85 and is categorized as a significant improvement based on Hake's rule. Student result classified medium since it is slightly above the minimum criteria score in the pretest, which is the mean score is 70.8. Then it increases to the mean score of 95.8 in the post-test that shows the improvement of the student's solution-finding ability.

To evaluate student solution-finding, they are given the essay question that forces them to analyze the most suitable solution. It can be seen in Figure 9, and students are already able to propose a complex solution from a different perspective. To produce solutions, this method

\footnotetext{
To cope with the impact of the Yogyakarta earthquake, the Government issued Regulation of the Minister of Public Works Number: 19 / PRT / M / 2006 concerning Guidelines for the rehabilitation and reconstruction of houses after the earthquake in the province of D.I Yogyakarta and Central Java province. In your opinion, what strategy should the government carry out with regard to earthquake management in addition to issuing post-disaster regulations?
}

After the government issues a regulation, the next strategy that the government should take is to socialize to the people the importance of awareness of earthquakes and how to overcome them. so that people can digest and follow the government's advice.

Figure 9 Student's answer in solution-finding question 
involves student imagination or divergent thinking abilities, and students can assess the evaluative abilities of divergent thinking tasks. That evaluative capacity is correlated with divergent thinking ability.

Using STEM Project-Based Learning, students are introduced to the presentation and evaluation stage. The student can also present their design and the final project to all the students and teachers. Students need to mention their project strengths and weaknesses and receive advice from other students and teachers to make their project results better in the future. This learning activity developed student solution-finding. Therefore, when they face another problem, they are already familiar with the evaluation and developing solution.

Earthquake resistant building is planned to resist the largest earthquake of a distinct possibility that is expected to happen at their location. This suggests that the loss of life can be minimized by preventing unusual earthquake buildings' collapse (BigRentz, 2020). Their project needs to answer this challenge. However, along with the projectmaking process, the students also faced many problems choosing the suitable material, the right length, choosing the right glue, and another problem. Because this project is an individual task, they have to solve it by themselves. If students already possess these skills, they can propose the best solutions to solve the problems. Students will sense the utility as students consider the relationship between their expertise and the actual problem. This also improves their (cognitive) and (psychomotor) abilities. This finding is in line with the statement by Henderson (2005) that the STEM PBL explains the topic better conceptually. The method of product design enables students through STEM to position and express their understanding of the concepts. Therefore students with good understanding and skill have a better chance of solving the difficulties they face.

\section{CONCLUSION}

The implementation of STEM Project-Based Learning can develop students' Problem Solving Skills. The N-gain result suggests a substantial improvement between the pretest and the post-test treatment can be verified. The Idea-Finding aspect has the most significant improvement, and the lowest improvement is in the FactFinding aspect, although categorized as a medium improvement. This suggests that the problem-solving abilities of students are greatly enhanced by implementing STEM Project-Based Learning. STEM Project-Based Learning trained students to define the problem and analyze the solution using their knowledge in science, technology, engineering, and mathematics. According to these research results, some recommendations can be used as potential guides for other research. This is important to allow the student to adjust to the new treatment and for the instructor to fully understand the need of the student and what kind of instructions need to be provided to the students to apply their best STEM Project-based learning treatment, thus achieve better data and results.

\section{ACKNOWLEDGMENT}

The authors acknowledge SMP Alfa Centauri for permission to obtain the research data.

\section{REFERENCES}

Apriyani, R., Ramalis, T. R., \& Suwarma, I. R. (2019). Analyzing Student's Problem Solving Abilities of Direct Current Electricity in STEM-based Learning. Journal of Science Learning, 2(3), 85-91. https://doi.org/10.17509/jsl.v2i3.17559

Arisanti, W. O. L., Sopandi, W., \& Widodo, A. (2016). Analisis Penguasaan Konsep dan Keterampilan Berpikir Kreatif Siswa SD Melalui Project Based Learning. EduHumaniora|Jurnal Pendidikan Dasar Kampus Cibiru, 8(1), 82-95.

Arreola, N. J., \& Reiter-Palmon, R. (2016). The effect of problem construction creativity on solution creativity across multiple everyday problems. Psychology of Aesthetics, Creativity, and the Arts, 10(3), 287-295. https://doi.org/10.1037/a0040389

BNPB. (2020). Data Informasi Bencana Indonesia (DIBI). Retrieved from https://bnpb.cloud/dibi/

Benedek, M., Nordtvedt, N., Jauk, E., Koschmieder, C., Pretsch, J., Krammer, G., \& Neubauer, A. C. (2016). Assessment of creativity evaluation skills: A psychometric investigation in prospective teachers. Thinking Skills and Creativity, 21, 75-84. https://doi.org/10.1016/j.tsc.2016.05.007

Bhakti, Y. B., Astuti, I. A. D., Okyranida, I. Y., Asih, D. A. S., Marhento, G., Leonard, L., \& Yusro, A. C. (2020). Integrated STEM Project Based Learning Implementation to Improve Student Science Process Skills. Journal of Physics: Conference Series, 1464(1). https://doi.org/10.1088/1742-6596/1464/1/012016

BigRentz. (2020). How Earthquake-Proof Buildings Are Designed. Retrieved from https://www.bigrentz.com/blog/earthquake-proofbuildings

Capraro, M. M., \& Jones, M. (2013). Interdisciplinary STEM projectbased learning. STEM Project-Based Learning an Integrated Science, Technology, Engineering, and Mathematics (STEM) Approach, 51-58. https://doi.org/10.1007/978-94-6209-143-6 6

Chang, C. Y., \& Weng, Y. H. (2002). An exploratory study on students' problem-solving ability in earth science. International Journal of Science Education, 24(5), 441-451. https://doi.org/10.1080/09500690110066502

CNN Indonesia. (2019). BMKG: Jepang Sudah Wajibkan Bangunan Anti Gempa Sejak $1990 . \quad$ Retrieved from https://www.cnnindonesia.com/teknologi/20191003112012199-436323/bmkg-jepang-sudah-wajibkan-bangunan-anti-gempasejak-1990

Cropley, A. (2006). In praise of convergent thinking. Creativity Research Journal, 18(3), 391-404.

Deniz, M. (2004). Investigation of the Relation between Decision Making Self-Esteem, Decision Making Style and Problem Solving Skills of University Students. Eurasian Journal of Educational Research (EJER), (15).

Earthquake Track. (2020). Recent Earthquakes Near Indonesia. Retrieved from https://earthquaketrack.com/p/indonesia/recent

Gustiani, I., Widodo, A., \& Suwarma, I. R. (2017). Development and validation of science, technology, engineering and mathematics (STEM) based instructional material. In AIP Conference Proceedings (Vol. 1848, No. 1, p. 060001). AIP Publishing LLC.. https://doi.org/10.1063/1.4983969

Guthrie, J. T., Schafer, W. D., Von Secker, C., \& Alban, T. (2000). Contributions of instructional practices to reading achievement in 
a statewide improvement program. Journal of Educational Research, 93(4), 211-225. https://doi.org/10.1080/00220670009598710

Grohman, M., Wodniecka, Z., \& Kłusak, M. (2006). Divergent thinking and evaluation skills: Do they always go together?. Journal of Creative Behavior, 40(2), 125-145.

Hake, R. R. (1998). Interactive-engagement versus traditional methods: A six-thousand-student survey of mechanics test data for introductory physics courses. American Journal of Physics, 66(1), 6474. https://doi.org/10.1119/1.18809

Hanif, S., Wijaya, A. F. C., \& Winarno, N. (2019). Enhancing Students' Creativity through STEM Project-Based Learning. Journal of Science Learning, 2(2), 50. https://doi.org/10.17509/isl.v2i2.13271

Henderson, C. (2005). Strategies for the Development of Student Problem Solving Skills in the High School Physics Classroom. Am. J. Physics, 59(10), 891-897.

Heffernan, K., \& Teufel, S. (2018). Identifying problems and solutions in scientific text. Scientometrics, 116(2), 1367-1382. https://doi.org/10.1007/s11192-018-2718-6

Jua, S. K. , Sarwanto, \& Sukarmin. (2018). The profile of students' problem-solving skill in physics across interest program in the secondary school. In Journal of Physics: Conference Series (Vol. 1022, No. 1, p. 012027). IOP Publishing.

Lou, S. J., Chou, Y. C., Shih, R. C., \& Chung, C. C. (2017). A study of creativity in $\mathrm{CaC} 2$ steamship-derived STEM project-based learning. Eurasia Journal of Mathematics, Science and Technology Education, 13(6), 2387-2404. https://doi.org/10.12973/EURASIA.2017.01231A

Maydeu-Olivares, A., \& D'Zurilla, T. J. (1997). The factor structure of the problem solving inventory. European Journal of Psychological Assessment, 13(3), 206-215. https://doi.org/10.1027/10155759.13.3.206

Nuraziza, R., \& Suwarma, I. R. (2018). Menggali Keterampilan Creative Problem Solving Yang Dimiliki Siswa SMP Melalui Pembelajaran IPA Berbasis STEM [Exploring the Creative Problem Solving Skills of Junior High School Students Through STEM-Based Science Learning]. WaPFi (Wabana Pendidikan Fisika), 3(1), 55. https://doi.org/10.17509/wapfi.v3i1.10941

Netwong, T. (2018). Development of Problem Solving Skills by Integration Learning Following STEM Education for Higher Education. International Journal of Information and Education Technology, 8(9), 639-643 https://doi.org/10.18178/ijiet.2018.8.9.1114

OECD. (2019). PISA 2018 Results: Combined Executive Summaries, Volume I, II \& III. Retrieved from https://www.oecd.org/pisa/Combined Executive Summaries P ISA 2018.pdf

Osborn, A. F. (1963). Applied imagination; principles and procedures of creative problem-solving. Scribner.

Schlegel, R. J., Chu, S. L., Chen, K., Deuermeyer, E., Christy, A. G., \& Quek, F. (2019). Making in the classroom: Longitudinal evidence of increases in self-efficacy and STEM possible selves over time. Computers \& Education, 142, 103637. https://doi.org/10.1016/j.compedu.2019.103637

Tseng, K. H., Chang, C. C., Lou, S. J., \& Chen, W. P. (2013). Attitudes towards science, technology, engineering and mathematics (STEM) in a project-based learning (PjBL) environment. International Journal of Technology and Design Education, 23(1), 87-102 https://doi.org/10.1007/s10798-011-9160-x

Treffinger, D. J., Isaksen, S. G., \& Stead-Dorval, K. B. (2005). Creative problem solving: An introduction. Prufrock Press Inc.

Whitten, S., \& Graesser, A. C. (2003). Comprehension of text in problem solving. In J. E. Davidson \& R. J. Sternberg (Eds.), The psychology of problem solving (pp. 207-229). New York, NY: Cambridge University Press.

Yuliati, L., Riantoni, C., \& Mufti, N. (2018). Problem solving skills on direct current electricity through inquiry-based learning with PhET simulations. International Journal of Instruction, 11(4), 123-138. https://doi.org/10.12973/iji.2018.1149a 